\title{
Physical and biological factors contributing to changes in the relative importance of recruitment to population dynamics in open populations
}

\author{
Daphne M. Munroe ${ }^{1,2, *}$, Takashi Noda ${ }^{1}$ \\ ${ }^{1}$ Faculty of Environmental Science, Hokkaido University, N10 W5, Kita-ku, Sapporo, Hokkaido 060-0810, Japan \\ ${ }^{2}$ Department of Fisheries \& Aquaculture, Vancouver Island University, 900 5th St., Nanaimo, British Columbia V9R 5S5, \\ Canada
}

\begin{abstract}
Changes in population dynamics of open populations are driven by variability in recruitment and post-recruitment processes. The relative importance of these 2 processes varies within and among populations depending on numerous physical and biological variables. We examined variables that determine the correlation between recruitment and population density in 2 populations of intertidal barnacles (Chthamalus spp.). Data were collected over 5 yr at 59 rocky shore sites with various physical and biological characteristics. We tested the influence of recruitment density, recruitment variability, barnacle species, available free space, surface temperature, rugosity, wave intensity, and density of predators on the correlation (Fisher transformed correlation coefficient $r_{z}$ ) between recruitment and changes in population coverage. We compared linear models including $r_{z}$ and all possible combinations of physical and biological characteristics measured at each site using Akaike's information criterion (AIC). The effect of each variable deemed important by AIC was determined using partial regression plots. Results showed that the most important variables (and their direction of influence) in determining correlation among recruitment and population density were recruitment density (positive), recruitment variability (positive), rugosity (negative), available free space (positive), and wave intensity (positive). The influence of individual variables and combinations of variables changed spatially and temporally. This study showed that recruitment is an important variable determining the population dynamics in open populations but that post-recruitment factors can also influence the correlation between recruitment and population density. It is also clear that the combination and strength of variables influencing population density change over spatial and temporal scales.
\end{abstract}

KEY WORDS: Population dynamics ' Recruitment and post-recruitment processes · Barnacle Chthamalus $\cdot$ Meta-analysis

\section{INTRODUCTION}

A cornerstone of population ecology is identifying and understanding the drivers of population dynamics. At one extreme, population dynamics could depend entirely on influx of new individuals; this case is called 'recruitment limitation' and is considered to exist in systems that are density independent (Sutherland 1987). At the other extreme, we could consider systems that are controlled entirely by density-dependent post- recruitment processes. In reality, neither extreme is likely; instead, a balance of recruitment and postrecruitment factors determines the dynamics of a population (Caley et al. 1996, Chesson 1998), but what is less well understood is the nature of that balance and conditions that can shift or modify it (Menge 2000).

Examination of the influence of larval and recruitment processes on adult population ecology is not new (Thorson 1950, Connell 1961, Meadows \& Campbell 1972, Crisp 1974), and considerable debate over the 
relative influence of larval influx on community dynamics has continued for decades (Morgan 2001). Empirical study of marine larvae is difficult, particularly in open populations where tracking larvae in the ocean and accurately quantifying larval settlement is challenging. Ecosystems where initial settlement patterns are discernible and permanent, such as barnacles on the rocky shore, present a convenient and in many cases easily accessible way around these issues. For this reason, barnacles on the rocky shore have been the subject of numerous studies in population and community ecology, and a great deal is understood about their biology and ecology (Lewis 1964, Schiel 2004).

We can identify systems where evidence of a direct influence of larval recruitment on population dynamics exists; in a study spanning local and regional spatial scales over 5 yr, Noda (2004a) showed that population densities of barnacles strongly reflected recruitment densities. Many studies have observed that these correlations among recruitment and population tend to be strongest in cases where recruitment is low (Underwood \& Denley 1984), but they do not hold for high recruitment levels where there is greater opportunity for post-recruitment factors to operate (Roughgarden et al. 1988, Carroll 1996, Menge 2000). This idea has previously been called the recruit-adult hypothesis (Menge 2000). Connolly et al. (2001) tested the recruit-adult hypothesis by examining the relative importance of recruitment to population fluctuations along the North American Pacific coast. They argued that, as latitude decreases, upwelling-supplied larval densities decrease, recruitment also decreases, and the relative importance of recruitment in population dynamics should increase. Thus, the recruit-adult hypothesis predicts that as recruitment increases, the relative importance of recruitment in population dynamics should decrease.

In addition to the influence of recruitment density, the variability of recruitment has also been identified as influencing the relative importance of recruitment to population dynamics (Noda 2004a, Svensson et al. 2004). Using model simulations, Svensson et al. (2004) demonstrated that recruitment variability has great importance in population dynamics. Noda (2004a) confirmed this model prediction with empirical evidence showing that variability in barnacle recruitment can determine barnacle population dynamics, as well as population dynamics of its gastropod predator.

Post-recruitment factors can modify populations via alteration of population vital rates (growth and survival). Many local physical and biological variables can alter growth and survival in a population and thereby influence the relative importance of recruitment and post-recruitment factors in population dynamics. Stud- ies testing the relative influence of recruitment and post-recruitment factors on population dynamics have been carried out for decades (Connell 1961, Meadows \& Campbell 1972, Crisp 1974); however, few have examined the biological and physical factors that alter the relative influence of recruitment on population dynamics.

One variable that has been shown to alter the relative influence of recruitment on population dynamics is free space availability (Gaines \& Roughgarden 1985, Svensson et al. 2004). Barnacle settlers require open or free space on intertidal surfaces on which to settle, meaning that at higher sessile community densities (less free space), settlement success is reduced. Therefore, we could predict that as available space increases, the relative importance of recruitment in population dynamics should increase. Svensson et al. (2004) found that including free space in models of barnacle population dynamics among sites in northern Europe accurately represented the dynamics of real populations, highlighting its importance in population dynamics.

Species differences have also been identified as variables that can alter the relative importance of recruitment to population dynamics (Menge 2000). In a study in Oregon, the relative influence of recruitment on population density was compared in 2 barnacle species. The species with greater stress tolerance showed greater influence of recruitment on adult population density (Menge 2000), meaning that certain speciesspecific characteristics themselves can alter the relationship among recruitment and population dynamics.

Habitat complexity has been shown to influence the relative importance of recruitment versus post-recruitment processes on population dynamics (Johnson 2007). In an investigation of population dynamics of blue rockfish, Johnson (2007) found that increasing habitat complexity (defined as vertical relief of the reef) caused increased post-settlement survival and increased influence of recruitment on population. For barnacles, habitat complexity could be measured using surface roughness or rugosity. Barnacle post-settlement survival increases with settlement in rugose habitats (Wethey 1986, Walters \& Wethey 1996), and therefore rugosity of intertidal surfaces may increase the relative importance of recruitment to population dynamics for barnacles.

We further suggest that rocky shore habitats are an environment where wave and thermal stress can modify the relative influence of recruitment and postrecruitment processes on populations. Through their influence on larval settlement processes (waves, Forde \& Raimondi 2004, Power et al. 2006; temperature, Pineda et al. 2002) and post-settlement survival (waves, Denny 1985; temperature, Foster 1971, Raimondi 1990), these variables could be important modi- 
fiers of how strongly recruitment determines population dynamics. We could predict that if thermal stress and wave force caused a decrease in settler survival, increasing these variables should decrease the relative importance of recruitment in population dynamics. To our knowledge, neither of these variables has been tested for their influence on the relative importance of recruitment or post-recruitment processes on population dynamics.

Our goal in this study was to consider the correlation among recruitment and population dynamics at multiple hierarchically located sites with a variety of physical and biological characteristics over 5 yr to determine how the variables discussed above change the relative importance of recruitment to population dynamics (Noda 2004b). Using recruitment sites of cleared nearly vertical rock faces, we were able to assess relative larval settlement rates without density-dependent effects of adults on settlement (intra- and interspecific competition, Chesson 1998) and on a natural settlement substrate (Pineda et al. 2002). We tested the influence of the following variables on the correlation between recruitment and changes in population cover (hereafter called r-recruit: $\Delta$ cover): recruitment density, recruitment variability, barnacle species, free space availability, rock temperature, rugosity, wave intensity, and predator density. We were interested in identifying which variables influence this correlation, spatial patterns that may emerge, and how the influence of these variables may shift temporally. biogeographical features can be found in Okuda et al. (2004) and Nakaoka et al. (2006).

Barnacle species observed at all shores were identified at the outset of the study period by taking representative individuals from each shore and sending them to a taxonomic laboratory for species confirmation. Individuals observed in the northernmost region (Doto) were exclusively Chthamalus dalli. The main recruitment period for C. dalli is summer (August, Kado 2003). The species identified in the southern 2 regions (Donan and Sanriku) was $C$. challengeri. This species has the highest seasonal recruitment in this area from July to October (Iwaki 1975) and is commonly found on natural rock substrate (Miyamoto et al. 1999). Chthamalid species in Japan are strong spatial competitors and are generally only outcompeted by mussels (Kado 2003); however, mussel coverage was low at our sites. Both species live intertidally, and their main predators include gastropods (Nucella lima, Thais clavigera, and Ceratostoma inornatus) and an asteroid (Leptasterias ochotensis similispinis) (T. Noda pers. obs.).

Recruitment sites were cleared of all surface organisms each summer during low tide events in August by burning and then scraping the rock surface with a wire brush. Sampling of recruitment sites occurred approximately $125 \mathrm{~d}$ after clearing to assess the magnitude of recruitment during the major recruitment period for both species every year, beginning in 2003 and continuing until 2007. Sampling of recruitment sites involved photographing $5 \mathrm{~cm} \times 5 \mathrm{~cm}$ quadrats using a Canon

\section{MATERIALS AND METHODS}

Field census. Intertidal rocky shore sites along the Pacific coast of northern Japan were used to monitor barnacle recruitment and population dynamics between 2003 and 2008. A hierarchical design (Noda 2004b) was used for layout of study sites, with 5 shores nested within each of 3 regions, and 5 sites within each shore for a total of 75 study sites (Fig. 1). The 3 regions were separated by several hundred $\mathrm{km}$; shores were separated by 5 to $25 \mathrm{~km}$; sites were separated by 10 to $50 \mathrm{~m}$. At each site, adjacent recruitment and control sites, separated by several tens of $\mathrm{cm}$, were marked with permanent anchors drilled into roughly vertical rock delimiting study areas that were $100 \mathrm{~cm}$ vertically by $50 \mathrm{~cm}$ horizontally centered at mid-tide. Maximum tidal amplitude at this study area is ca. $160 \mathrm{~cm}$. Additional descriptions of the study sites and their

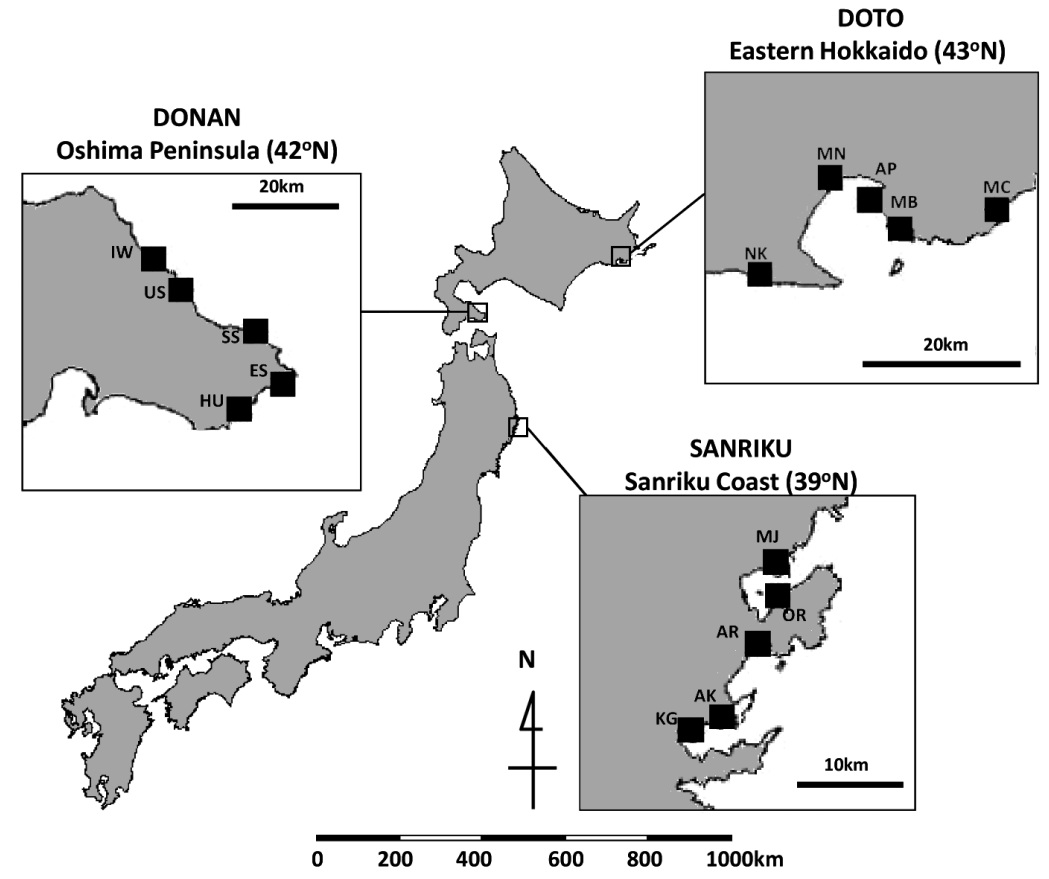

Fig. 1. Study regions and shores within northern Japan. Five sites were located within each of 5 shores in 3 regions; shores are shown by solid black boxes and labeled with a unique letter code 
IXY Digital 320 camera (macro setting and 180 dpi at a distance of $10 \mathrm{~cm}$ from the rock surface). Eight replicate quadrat photographs taken within $15 \mathrm{~cm}$ above and $15 \mathrm{~cm}$ below mid-tide level at each site were counted and used to estimate barnacle recruitment density (recruits $25 \mathrm{~cm}^{-2}$ ) at each site in each year. Recruitment to these sites over the time period used here involved only barnacle recruitment (almost no recruitment of other organisms), making identification of individuals simple and consistent.

Control sites were censused each spring, summer, and autumn beginning in summer 2003 and continuing through summer 2008. Estimates of barnacle coverage were obtained using a grid overlain on the sample site with observation points at evenly spaced intervals (5 cm vertically and $5 \mathrm{~cm}$ horizontally, 200 grid points total). Presence or absence of barnacles at each point on the grid was used to estimate total barnacle coverage for each control site at each census. Change in barnacle coverage ( $\Delta$ cover) was calculated for 3 time periods each year. The time periods overlapped, and all 3 periods began at the time of recruitment site clearing and ended at either 4, 8, or 12 mo later, calculated at each site as follows, with subscript $t$ indicating the year at the time of recruitment:

$\Delta$ Cover $4 \mathrm{mo}_{(t)}=$

Percentage Cover Fall $(t)$ - Percentage Cover $\operatorname{Summer}_{(t)}$

$\Delta$ Cover $8 \mathrm{mo}_{(t)}=$

Percentage Cover Spring ${ }_{(t+1)}$-Percentage Cover $\operatorname{Summer}_{(t)}$

$\Delta$ Cover $12 \mathrm{mo}_{(t)}=$

Percentage Cover Summer $(t+1)$ - Percentage Cover

$\operatorname{Summer}_{(t)}$

At each site, a number of other physical and biological variables were measured. Percentage of bare rock at each control site was calculated from observations made using grid counts of bare space as described above for assessment of barnacle cover on control sites.

Maximum rock surface temperature was measured at one site within each shore using a temperature logger (StowAway Tidbit, Onset Computer) fixed to the rock surface at mid-tide level using marine epoxy (Splash Zone E380, Konishi). Each logger recorded temperature every 6 min from July to November 2006. Rock surface temperature at all sites within each shore was measured during each low tide visit using a radiation thermometer (IT-540NH, Horiba). Extrapolation of maximum summer rock surface temperature from sites measured with loggers to the remaining sites was done using multiple regression with measurements made by the radiation thermometer and highest logged temperatures $\left(\mathrm{R}^{2}\right.$ of the regressions was $\left.0.69, \mathrm{SE}=0.03\right)$.
Rugosity of the rock surface was measured at the outset of the study on each recruitment site after clearing all surface organisms. Measurements were made using a pattern recording gauge (Katatori-gauge, Shinwa-sokutei) to measure linear distance over the rock surface and distance along the surface contour. The ratio of contour distance over linear distance was used to estimate rugosity; average rugosity for each site was calculated from 8 replicate measures over $15 \mathrm{~cm}$ linear distance each.

Maximum monthly wave force was measured using a maximum velocity recorder as described by Bell \& Denny (1994). A force recorder was deployed at midtide $50 \mathrm{~cm}$ to the side of each site for six 1 mo intervals between summer 2003 and summer 2004. Average maximum monthly wave force was used as wave intensity for each site.

Density of all mobile predators found within the recruitment area at each site during each census was calculated. Average density of mobile predators at each site was calculated from individual density estimations.

Data analysis. Correlations between recruitment density and change in barnacle coverage (r-recruit: $\Delta$ cover) for each time period $(4,8$, and $12 \mathrm{mo})$ were assessed using linear regression of average recruitment versus $\Delta$ cover for each site over the census period (5 yr). This variable (r-recruit: $\Delta$ cover) became the response variable in the study. At some sites, missing data or low recruitment and/or coverage meant that a correlation could not be accurately assessed. These sites were dropped from subsequent analysis, reducing the number of sites from 75 to 59. The Pearson's correlation coefficient obtained for each site was transformed using Fisher's z-transformation to normalize it and obtain the effect size appropriate for metaanalysis (Hillebrand 2004). The formula for Fisher's transformation of the correlation coefficient (r) is:

$$
\mathrm{r}_{z}=0.5 \times \ln \left(\frac{1+\mathrm{r}}{1-\mathrm{r}}\right)
$$

To evaluate which physical and biological variables influence the correlation between recruitment and barnacle population dynamics, we compared linear models including r-recruit: $\Delta$ cover (dependent variable) and all possible combinations of physical and biological characteristics measured at each site (explanatory variables) using Akaike's information criterion (AIC; Akaike 1974). Prior to model comparison, a test for multicollinearity was performed using tolerance values (Quinn \& Keough 2002), and all independent variables were found to have acceptable tolerance values indicating low multicollinearity. All variables in the models were checked for normality, and normalizing transformations were applied as needed before model analysis. The model with the 
lowest AIC and all models with an AIC within 2 of the minimum were considered the best models. Model selection was conducted separately for all combinations of spatial scales (large scale and each regional scale) and temporal scale $(4,8$, and 12 mo cover change periods). Each model selection produced a set of best models, and the frequency of inclusion of each variable in each set was calculated.

For all variables that appeared in $100 \%$ of the best models (for all combinations of space and time), we plotted partial regression plots (also called added variable plots) to show the effect of adding that variable to the model (Chatterjee \& Hadi 2006). For each plot, the residuals of the regression of r-recruit: $\Delta$ cover against all variables, except the variable of interest, was used as the $y$ variable, and residuals from the regression of the variable of interest against all remaining variables was used as the $x$ variable. The use of residuals in ecol- ogy has been shown to be biased when the independent variables are correlated (Freckleton 2002); however, we confirmed low multicollinearity among the variables used here. The partial regression plots show the strength of the linear relationship among $r-$ recruit: $\Delta$ cover and each variable while keeping the effect of all other variables constant (Chatterjee \& Hadi 2006). Only significant partial regression plots (Bonferroni corrected $\alpha=0.025$ ) were included in the results.

\section{RESULTS}

\section{Spatiotemporal variability in correlation between recruitment and population dynamics}

Sites analyzed in this study showed various levels of the physical and biological variables tested, and the spatial variation of those variables is shown in Fig. 2. Like-
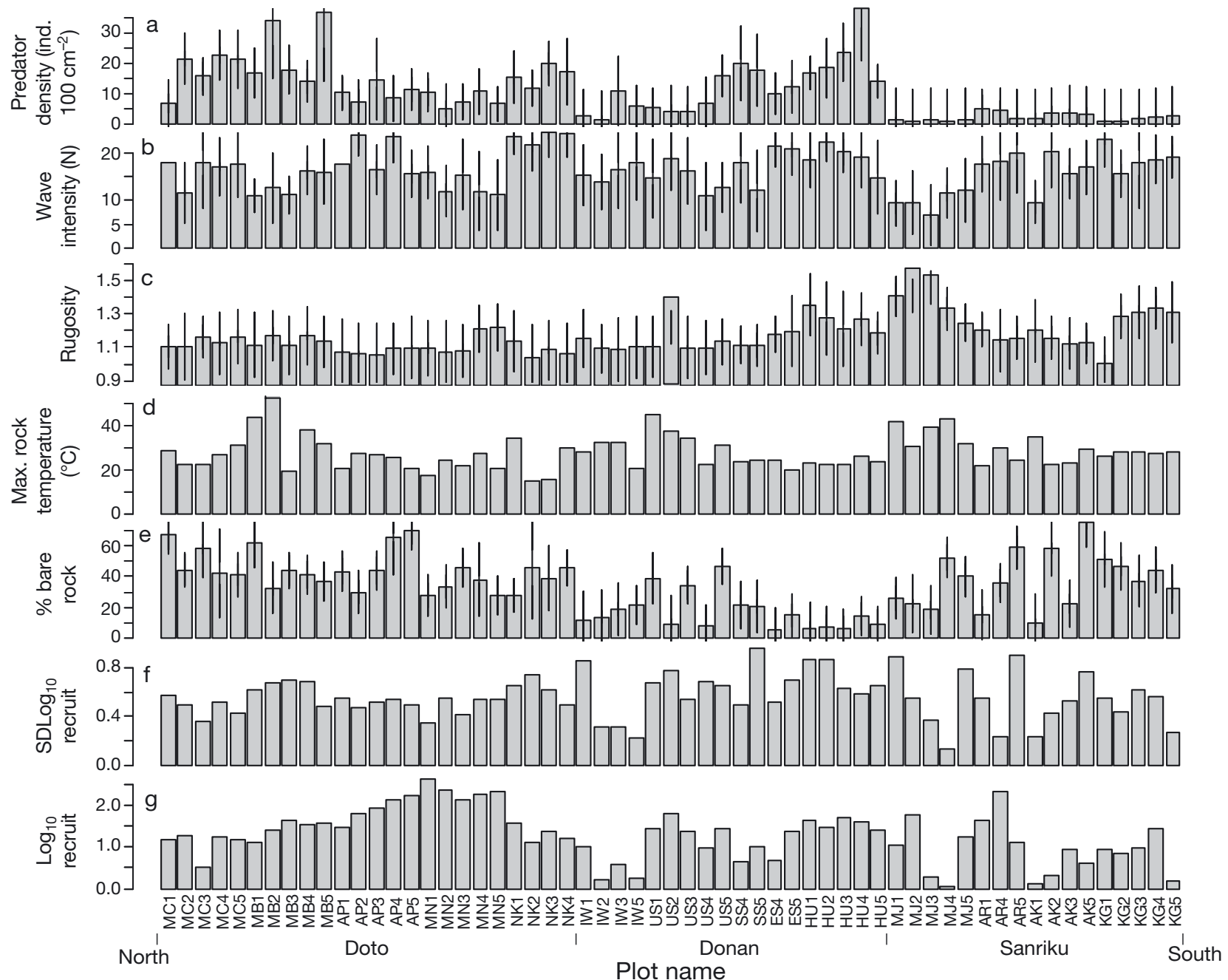

Fig. 2. Mean value for each physical and biological variable at each site. All variables shown here are untransformed except for recruitment and recruitment variability. Sites are arranged from the northern end of the study area (left) to the southern end (right). Lines indicate $\mathrm{SD}_{\text {; }}$ maximum rock temperature is a single value and has no variability, and $\mathrm{SD}$ of recruitment is shown in Panel g (bottom) 
wise, sites exhibited a range of correlations between recruitment and population dynamics (12 mo time scale: $\max \mathrm{r}=0.99, \min \mathrm{r}=-0.83 ; 8$ mo: $\max \mathrm{r}=0.98, \min \mathrm{r}=$ $-0.81 ; 4$ mo: $\max r=0.96$, $\min r=-0.64)$. Fig. 3 shows the spatial and temporal variation in correlation coefficients.

At the large spatial scale, over the 4 mo time scale, AIC resulted in 11 best models. On the 8 mo time scale, 12 models were ranked as best, with $100 \%$ including both variables recruitment density and species. For the longest time scale, 12 mo, AIC resulted in 30 best models, all of which contained the explanatory variable recruitment SD (Table 1).

In the Doto region, over the 4 mo time scale, AIC delivered 7 best models. The explanatory variable recruitment density was included in $100 \%$ of those best models. Over the 8 mo time scale, 9 best models were identified and again $100 \%$ of these contained the variable recruitment density. On the 12 mo time scale, out of the 8 best models, 100\% contained both recruitment and percentage of bare rock space (Table 1).

Over the 4 mo time scale in the Donan region, AIC identified 18 best models, and no individual variable was included in more than half of these; over the 8 mo time period, 8 best models were returned again with no variable appearing in all best models. Within the 12 mo time period, 10 models were considered best. Of those, $100 \%$ contained wave intensity and recruitment standard deviation (Table 1).

In the southernmost region, Sanriku, on the shortest time scale, 15 best models were returned, with none of the variables appearing in all models. Over the 8 mo time scale, only 5 models were identified as best, and all of these models contained recruitment density, wave intensity, and rugosity as explanatory variables. On the 12 mo scale, AIC identified 15 best models, with none of the variables appearing in all models (Table 1).

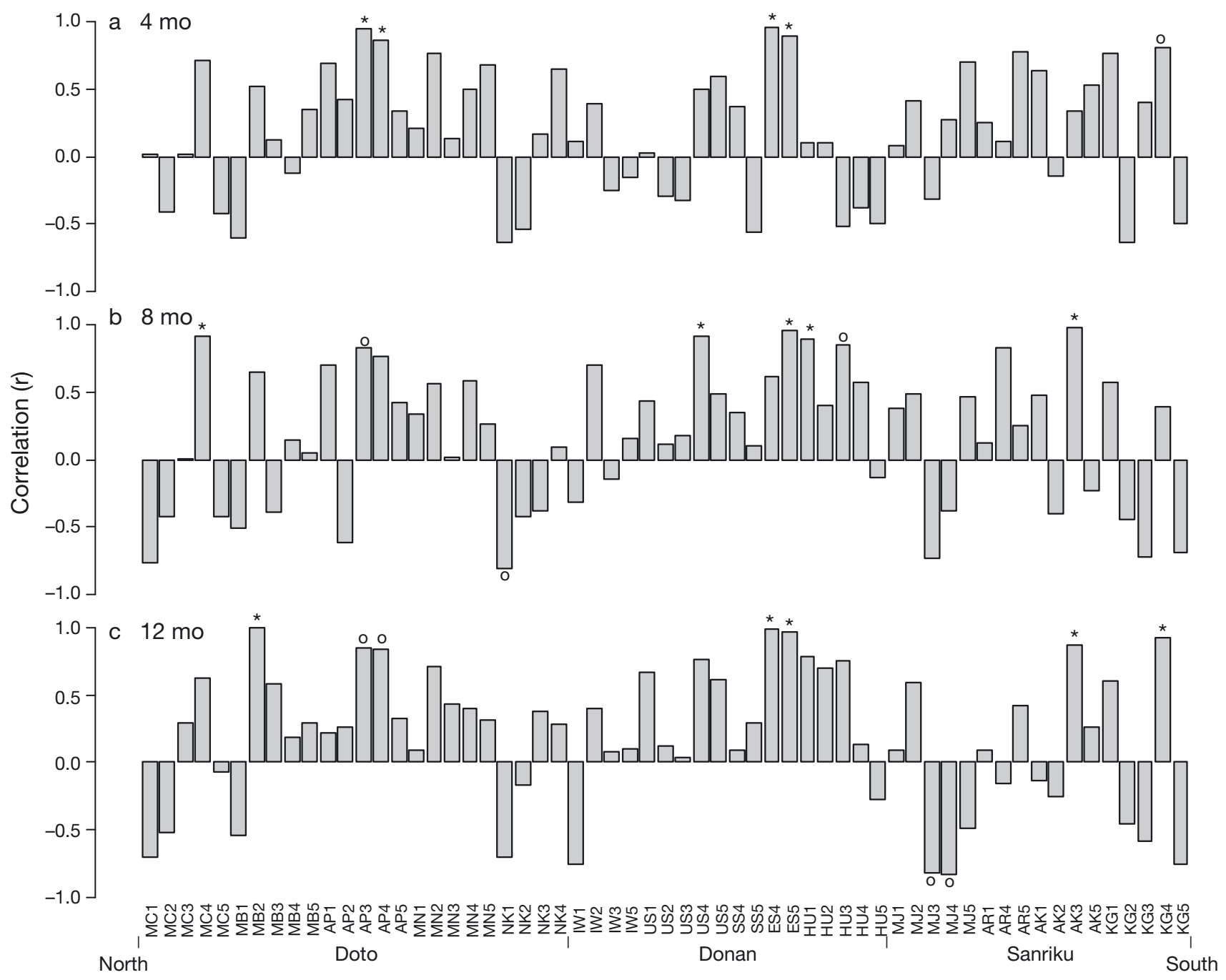

Fig. 3. Pearson's correlation coefficients (untransformed) for all sites. Sites are arranged from north to south (left to right). Correlation coefficients that are significant at $\alpha=0.05$ (*) or $\alpha=0.10$ (O) 
Table 1. Frequency of each variable in the set of best models for each spatial scale and temporal scale, based on Akaike Information Criterion (AIC) selection of best models. Frequencies of $100 \%$ shown in bold; significant partial regression marked with *. Values in italics show the number of best models included

\begin{tabular}{|lcccc|}
\hline & All regions & Doto & Donan & Sanriku \\
\hline $\mathbf{4}$ mo & 11 & 7 & 18 & 15 \\
Recruitment & 82 & $\mathbf{1 0 0}$ & 44 & 27 \\
Recruitment SD & 9 & 14 & 17 & 80 \\
Species & 9 & & & \\
Bare rock & 9 & 14 & 11 & 13 \\
Max. rock temperature & 9 & 14 & 22 & 7 \\
Rugosity & 73 & 14 & 17 & 67 \\
Wave intensity & 18 & 14 & 33 & 13 \\
Predators & 82 & 14 & 22 & 33 \\
$\mathbf{8}$ mo & 12 & 9 & 8 & 5 \\
Recruitment & $\mathbf{1 0 0}$ & $\mathbf{1 0 0}$ & 13 & $\mathbf{1 0 0}$ \\
Recruitment SD & 8 & 22 & 13 & 17 \\
Species & $\mathbf{1 0 0}$ & & & \\
Bare rock & 50 & 22 & 25 & 17 \\
Max. rock temperature & 8 & 11 & 88 & 17 \\
Rugosity & 83 & 11 & 13 & $\mathbf{1 0 0}$ \\
Wave intensity & 33 & 11 & 13 & $\mathbf{1 0 0}$ \\
Predators & 42 & 33 & 13 & 17 \\
12 mo & 30 & 8 & 10 & 13 \\
Recruitment & 57 & $\mathbf{1 0 0}$ & 50 & 85 \\
Recruitment SD & $\mathbf{1 0 0}$ & 0 & $\mathbf{1 0 0}$ & 31 \\
Species & 50 & & & \\
Bare rock & 33 & $\mathbf{1 0 0}^{*}$ & 20 & 8 \\
Max. rock temperature & 23 & 0 & 40 & 62 \\
Rugosity & 60 & 50 & 80 & 23 \\
Wave intensity & 60 & 50 & $\mathbf{1 0 0}$ & 15 \\
Predators & 17 & 50 & 40 & 8 \\
& & & & \\
\hline
\end{tabular}

\section{Physical and biological variables and correlation between recruitment and population dynamics}

Partial regressions plots for variables found in all models are shown in Figs. 4 to 6 for each region and in Fig. 7 for all regions.

Recruitment. Recruitment density appeared in 100\% of the best model set within the Doto region over all time intervals and was also included in $100 \%$ of the best models on the large scale and within Sanriku over the 8 mo time period. Partial regression plots for recruitment density in Doto over 12 mo (Fig. 4a), in Sanriku over 8 mo (Fig. 6a), and on the large scale over 8 mo (Fig. 7a) show that this variable is positively correlated with $\mathrm{r}$ recruit: $\Delta$ cover over these spatial and temporal scales.

Recruitment deviation. Recruitment deviation was observed in $100 \%$ of the best models in Donan and on the large scale over the 12 mo period. Partial regression plots for these spatial/temporal combinations are shown in Figs. 5b \& 7b, respectively. Both partial regression plots demonstrate a positive relationship between recruitment standard deviation and $r_{z}$.

Species. Species did not overlap among regions; therefore, this variable could only be included in mod- els for the largest spatial scale. On the 8 mo time scale, species was included in $100 \%$ of the best models, and the mean residual of r-recruit: $\Delta$ cover was larger for Chthamalus challengeri versus $C$. dalli, indicating that r-recruit: $\Delta$ cover may be larger for $C$. challengeri. It should be noted that this result is confounded with region and may not be a robust result.

Bare rock. Bare rock was included in $100 \%$ of the best models on the 12 mo scale in the Doto region. Partial regression for this variable (Fig. 4b) revealed a positive relationship between bare rock and r-recruit: $\Delta$ cover.

Rugosity. Rugosity was observed in all of the best models in Sanriku over 8 mo. Partial regression for this variable (Fig. 6b) showed a negative relationship among rugosity and r-recruit: $\Delta$ cover.

Wave intensity. Wave intensity was observed in $100 \%$ of the best models for Sanriku over 8 mo and Donan over 12 mo. Partial regression for Sanriku over 8 mo was non-significant and therefore not included here. Partial regression for Donan over 12 mo (Fig. 5a) showed a positive relationship among wave intensity and r-recruit: $\Delta$ cover.

\section{DISCUSSION}

Results of the correlation between recruitment density and change in population cover showed a range of correlations among sites (Fig. 3). Sites exhibited various levels of physical and biological variables (Fig. 2), allowing us to test the influence of these variables on correlation between recruitment and population dynamics (r-recruit: $\Delta$ cover) over 5 yr under natural conditions. Many previous analyses have provided interesting results but have been unable to address correlation over longer temporal and spatial scales. In this study we are able to utilize a multi-variable and multi-year approach that is desirable for addressing these relationships on a large scale (Caley et al. 1996). Here, both recruitment and biological and physical postrecruitment factors influenced the correlation between recruitment and population coverage dynamics. The influence of these variables on the correlation changed with the temporal and spatial scale under consideration.

Connolly et al. (2001) proposed that a coastal latitudinal trend in the relative importance of recruitment to 

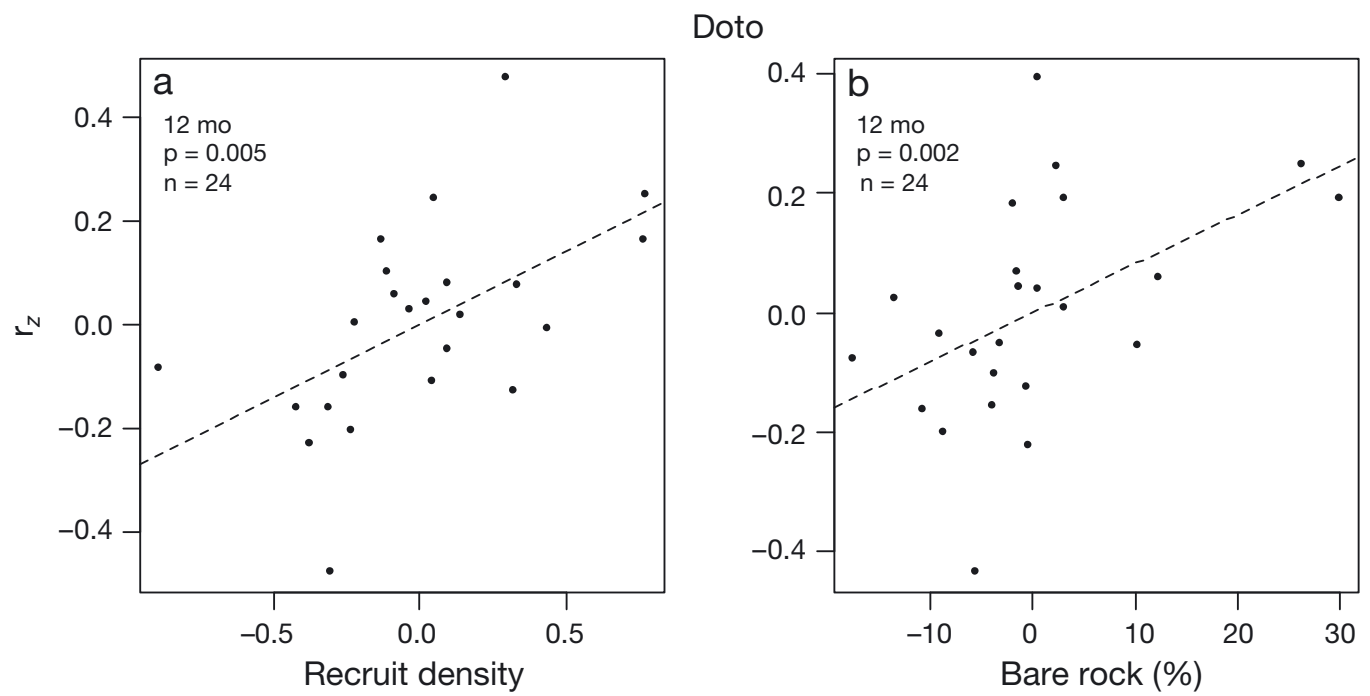

Fig. 4. Partial regression plots for variables found in all models (bold values with * in Table 1) from Doto Region. Residuals of (a) recruitment density versus r-recruit: $\Delta$ cover on a 12 mo time scale and of (b) percentage of bare rock versus r-recruit: $\Delta$ cover on a 12 mo time scale

population fluctuations could exist along the American Pacific coast. They argued that, as latitude decreases, upwelling-supplied larval densities decrease, recruitment also decreases, and the relative importance of recruitment in population dynamics increases (the recruit-adult hypothesis). In our examination of 59 sites on a coastwide scale, we failed to observe an obvious latitudinal pattern in r-recruit: $\Delta$ cover (Fig. 3). We did observe evidence concerning the recruit-adult hypothesis; this will be discussed in the following section. A possible reason for our failure to observe a latitudinal pattern in r-recruit: $\Delta$ cover is the lack of an upwellingdriven latitudinal trend in recruitment, as is seen along the American Pacific coast (Roughgarden et al. 1988).

\section{Recruitment}

The recruit-adult hypothesis has been suggested to explain variation in the influence of recruits to adult populations such that at low levels of recruitment, there is a strong influence on adult populations while

\section{Donan}
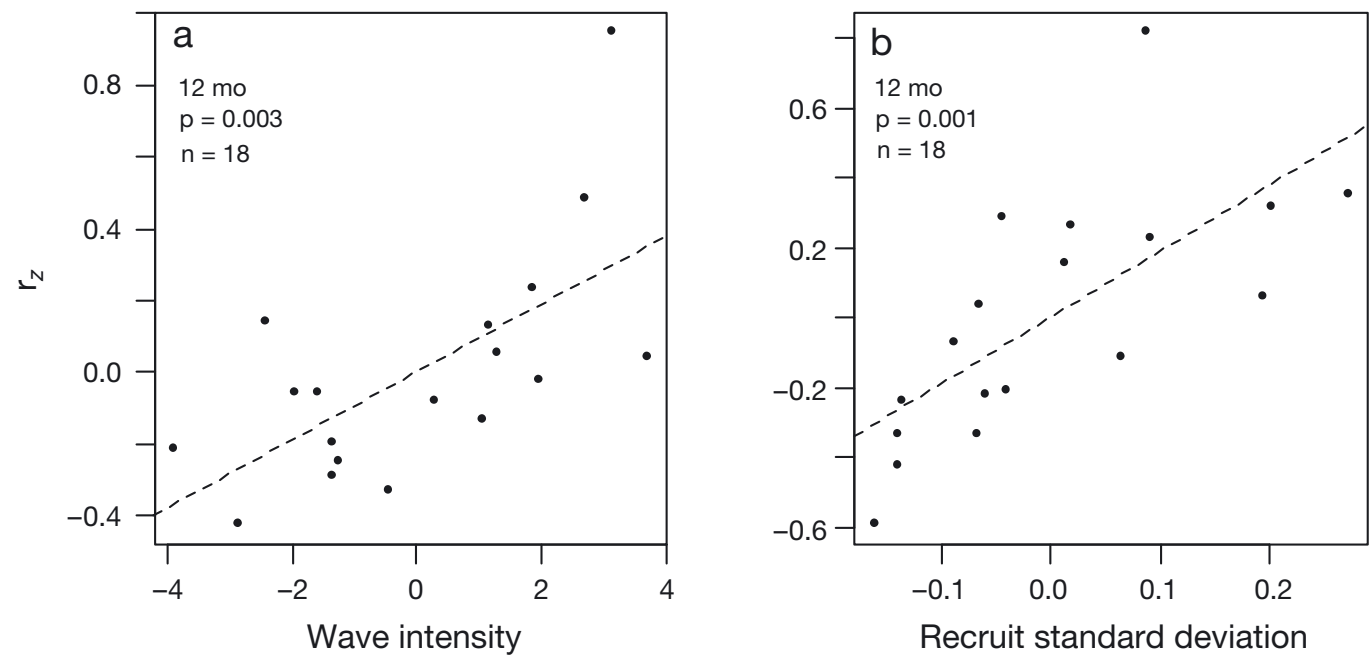

Fig. 5. Partial regression plots for variables found in all models (bold values with * in Table 1) from Donan Region. Residuals of (a) wave intensity versus r-recruit: $\Delta$ cover on a 12 mo time scale and of (b) recruitment SD versus r-recruit: $\Delta$ cover on a 12 mo time scale 


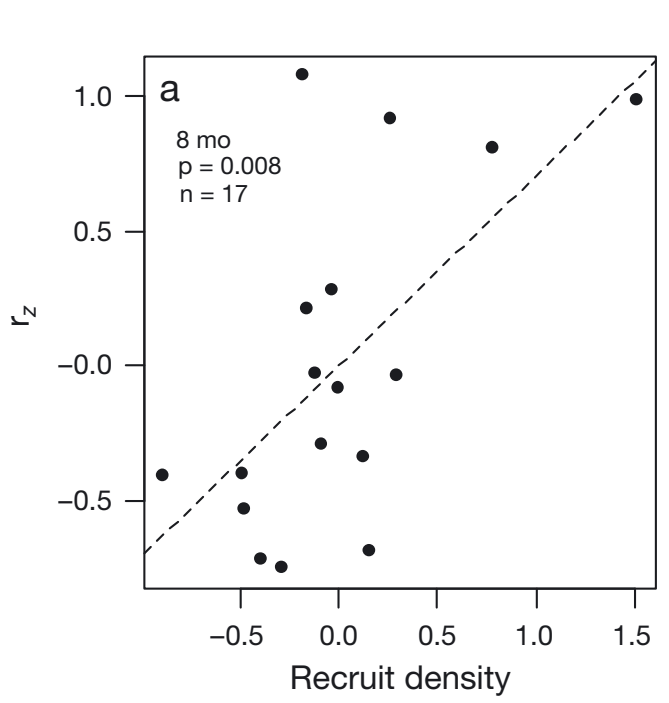

Sanriku

Fig. 6. Partial regression plots for variables found in all models (bold values with * in Table 1) from Sanriku Region. Residuals of (a) recruitment density versus r-recruit: $\Delta$ cover on an 8 mo time scale and of (b) rugosity versus r-recruit: $\Delta$ cover on an 8 mo time scale

at high recruitment, post-recruitment factors become more important and the influence of recruitment weakens (Roughgarden et al. 1988, Carroll 1996, Menge 2000). Previous studies have used $R^{2}$ as the metric with which to gauge the influence of recruitment density on population dynamics. For example, in a study performed in Oregon, USA, Menge (2000) observed higher correlation between recruitment intensity and final adult coverage at low recruitment densities for Chthamalus dalli. When considering $\mathrm{R}^{2}$, our data agreed with previous studies with the maxi- mum observed value of $\mathrm{R}^{2}$ decreasing with increased average recruitment, although large variation in $\mathrm{R}^{2}$ still remains for low to intermediate recruitment levels.

Here, we performed our analysis on the correlation coefficient because we observed high variation in $r$ among sites (Fig. 3) that included negative values, and the use of $\mathrm{R}^{2}$ would have misrepresented these negative correlations that have very different implications to the influence of recruitment on population dynamics. When we examined the relationship between recruitment density and r-recruit: $\Delta$ cover, we found a
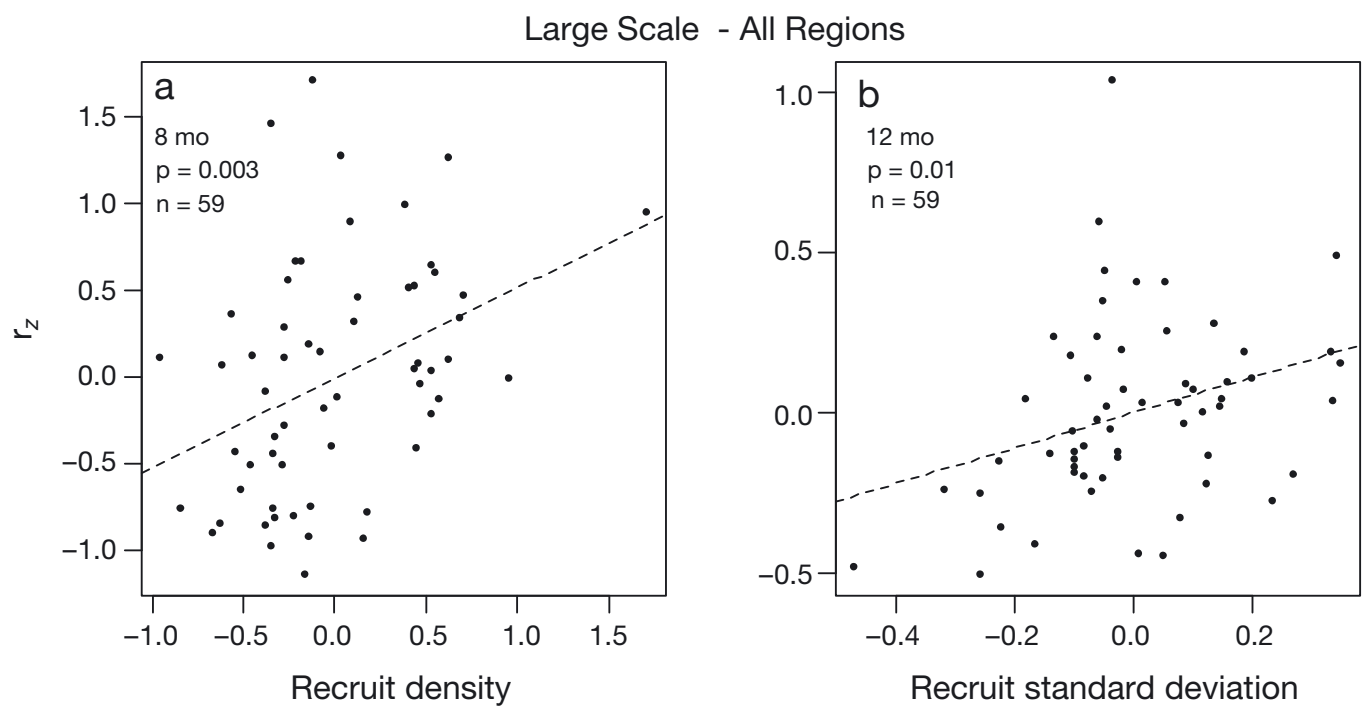

Fig. 7. Partial regression plots for variables found in all models (bold values with * in Table 1) from the large spatial scale (all regions combined). Residuals of (a) recruitment density versus r-recruit: $\Delta$ cover on an 8 mo time scale and of (b) recruitment SD versus r-recruit: $\Delta$ cover on a 12 mo time scale 
positive relationship when the effect of all other variables considered here was held constant (Figs. 4a, 6a, $\& 7 \mathrm{a}$ ), the opposite to that predicted by the recruitadult hypothesis. This result may suggest that in failing to account for the influence of a variety of other physical and biological characteristics, previous studies have misinterpreted a negative relationship between recruitment and population dynamics. It is also possible that by performing analyses using $\mathrm{R}^{2}$ instead of $\mathrm{r}$, previous studies have inadvertently grouped strong negative correlations with strong positive correlations. Another possible cause for this contradictory result is that by comparing recruitment densities from cleared rock spaces to adjacent populations which are part of complete communities, our study failed to include aspects of recruitment limitation that may be important in the recruit-adult phenomenon in natural populations.

\section{Recruitment deviation}

Svensson et al. (2004) conducted a study examining the importance of recruitment versus post-recruitment factors on population dynamics of Semibalanus balanoides at multiple locations over $1 \mathrm{yr}$. Their results showed that variability in recruitment can influence the relative importance of recruitment on adult population density. In our analysis, we examined the SD of recruitment as an explanatory variable in the 5 yr correlation between recruitment and population coverage (r-recruit: $\Delta$ cover). Our data indicate that as the SD of recruitment increases, the correlation between recruitment and changes in population coverage also increases (Figs. 5b \& 7b), suggesting a greater relative importance of recruitment on population dynamics where recruitment is most variable.

Through climate change and various other anthropogenic impacts, recruitment variability could potentially increase via processes such as phytoplankton bloom asynchronies and changes in oceanic circulation patterns. Such an increase in recruitment variability could lead to changes in the dynamics of recruitment and population densities in some regions and over large spatial scales.

\section{Species}

The influence of recruitment and post-recruitment factors on populations was tested for 2 species concurrently by Menge (2000). He showed that speciesspecific differences exist among the barnacles Chthamalus dalli and Balanus glandula. In our study, 2 species of barnacles occur and were compared. C. dalli was prominent in the northern region (Doto), and $C$. challengeri was found in the southern 2 regions (Donan and Sanriku). Because of the regional division of these 2 species, we were unable to test the influence of species on a within-region (intermediate) spatial scale. On the large spatial scale, species was a variable in all best models explaining the variation in r-recruit: $\Delta$ cover on the 8 mo time scale. Although this result is logical and supports previous studies, this result should be interpreted with caution because species is confounded with region, and the effect of the two cannot be separated.

\section{Bare rock}

Settling barnacle larvae require available space on which to attach and grow; thus, free space can represent competition in the rocky shore. Previous studies (Gaines \& Roughgarden 1985, Svensson et al. 2004) have shown that increased free space on rocky shores leads to increased rates of barnacle recruitment. Increases in free space can therefore be expected to lead to greater post-recruitment survival and thereby greater correlation between recruitment and population dynamics via decreased competition. Our results showed that in Doto over the 12 mo period, bare rock space was included in all of the best models explaining variation in r-recruit: $\Delta$ cover, and the two were positively correlated (Fig. 4b). This supports predictions from previous studies (Gaines \& Roughgarden 1985, Svensson et al. 2004), suggesting that areas with high free space availability will tend to show greater correlation among recruitment and population dynamics.

\section{Rugosity}

Habitat complexity can provide heterogeneity and refuge areas that could influence density-dependent mortality (Forrester \& Steele 2004). In a study on central Californian (USA) reefs, Johnson (2007) showed that habitat complexity alters the relative importance of pre- and post-recruitment factors in the population dynamics of blue rockfish. Barnacle settlers are also influenced by surface topography and select favorable surface roughness habitats allowing increased postsettlement survival (Wethey 1986, Walters \& Wethey 1996). If rugose habitats provide more suitable settlement substrates and increase post-settlement survival, we could expect that increasing rugosity would increase the relative influence of recruitment on population dynamics (increased r-recruit: $\Delta$ cover). Despite its known importance to barnacle settlement and survival, this study is the first to test the influence of sur- 
face roughness (habitat complexity) on the relative importance of recruitment and post-recruitment factors on barnacle population dynamics.

We found that in Sanriku over 8 mo, rugosity was a component in all of the best models explaining variance in r-recruit: $\Delta$ cover. Here, increased rugosity led to a decrease in r-recruit: $\Delta$ cover (Fig. 6b), indicating a greater relative importance of post-recruitment factors at higher habitat complexity. This could imply that higher rugosity provides better predator or competitor habitats and refuge. Alternatively, it may suggest that the higher rugosities observed here are not more suitable settlement habitats and leave recruits there exposed to greater post-recruitment mortality. The observation of a negative correlation between rugosity and r-recruit: $\Delta$ cover demonstrated here warrants further experimental study to shed light on the true mechanisms behind this relationship.

\section{Wave intensity}

Wave forces can impose stress on intertidal organisms by reducing feeding opportunities and increased mortality by dislodgement or impact (Denny 1985) and therefore can influence post-settlement survival or performance. Alternatively, some authors have shown that increased wave intensity can facilitate greater larval delivery (Forde \& Raimondi 2004, Power et al. 2006) and thus could influence recruitment densities. In these ways, wave force could lead to conflicting changes in the relative importance of recruitment and post-recruitment factors in population dynamics. In this study, we observed wave intensity to be an important explanatory variable of r-recruit: $\Delta$ cover in Donan over $12 \mathrm{mo}$. In this case, the influence of wave force on r-recruit: $\Delta$ cover was observed to be positive (Fig. 5a). This may indicate that in the Donan region, wave forces tend to have the greatest influence on larval flux, creating a positive relationship with r-recruit: $\Delta$ cover.

\section{Temporal scale}

Some variables were consistently observed in the best models for explaining the correlation between recruitment and population cover, while others varied depending on the time scale of observation. Recruitment density was observed in $100 \%$ of the top AIC models in all 3 time periods, indicating that the influence of recruitment on r-recruit: $\Delta$ cover is maintained through time. Alternatively, the remaining variables (wave intensity, bare rock, rugosity, recruitment deviation, species) were observed in all best models at only one time period each. This indicates that the temporal window of observation can strongly influence some variables that appear important in the correlation between recruitment and population dynamics.

Menge (2000) performed a similar analysis in which he tested the linear regression among recruit densities and subsequent population densities using both spring (February) and summer (August) endpoints (comparable to our 8 and 12 mo time scales, respectively). His results showed that differences in the correlation $\left(\mathrm{R}^{2}\right)$ between recruit density and subsequent population size depended on differences in the time scale used. A change in correlation over time could reflect an increase in the relative importance of post-recruitment factors within a population if the correlation always decreases over time. This was true based on data from Menge (2000); however, our sites varied in the change in correlation over time, ranging from a decrease in r-recruit: $\Delta$ cover of 1.40 to an increase of 1.23 (corresponds to a decrease of 0.44 and increase of 0.72 in $\mathrm{R}^{2}$; $\mathrm{R}^{2}$ provided here for comparison to Menge 2000). This result suggests that increasing the time elapsed between recruitment and population measurement does not always lead to an increased role of postrecruitment factors.

\section{CONCLUSIONS}

Our results show that at different spatial and temporal time scales, different variables were included in the best models for explaining the correlation between recruitment and changes in population coverage. Caley et al. (1996) and Chesson (1998) proposed that when considering drivers for population dynamics, neither pure post-recruitment control nor pure recruitment-driven systems are probable and that a mix of the two is most likely. Our data show that this mixture of recruitment and post-recruitment factors exists and the composition of the mixture and variables influencing it can change over spatial and temporal scales.

Acknowledgements. We are indebted to Team Iso, i.e. the students from the rocky shore research group at Hokkaido University who censused sites and photographed recruitment year after year. Early versions of the manuscript were greatly improved by comments from anonymous reviewers. Financial support for D.M.M. was provided by the Japan Society for the Promotion of Science (JSPS) Postdoctoral Fellowship Program.

\section{LITERATURE CITED}

Akaike H (1974) A new look at the statistical model identification. IEEE Trans Automatic Control 19:716-723

> Bell EC, Denny MW (1994) Quantifying 'wave exposure': a simple device for recording maximum velocity and results of its use at several field sites. J Exp Mar Biol Ecol 181: $9-29$ 
Caley MJ, Carr MH, Hixon MA, Hughes TP, Jones GP, Menge BA (1996) Recruitment and the local dynamics of open marine populations. Annu Rev Ecol Syst 27:477-500

Carroll ML (1996) Barnacle population dynamics and recruitment regulation in southcentral Alaksa. J Exp Mar Biol Ecol 199:285-302

Chatterjee S, Hadi AS (2006) Regression analysis by example, 4th edn. John Wiley and Sons, Hoboken, NJ

Chesson P (1998) Recruitment limitation: a theoretical perspective. Aust J Ecol 23:234-240

Connell JH (1961) The influence of interspecific competition and other factors on the distribution of the barnacle Cthamalus stellatus. Ecology 42:710-723

- Connolly SR, Menge BA, Roughgarden J (2001) A latitudinal gradient in recruitment of intertidal invertebrates in the Northeast Pacific Ocean. Ecology 82:1799-1813

Crisp DJ (1974) Factors influencing the settlement of marine invertebrate larvae. In: Grant PT, Mackie AM (eds) Chemoreception of marine organisms. Academic Press, New York, NY, p 177-265

Denny MW (1985) Wave forces on intertidal organisms: a case study. Limnol Oceanogr 30:1171-1187

> Forde SE, Raimondi P (2004) An experimental test of the effects of variation in recruitment intensity on intertidal community composition. J Exp Mar Biol Ecol 301:1-14

Forrester GE, Steele MA (2004) Predators, prey refuges, and the spatial scaling of density-dependent prey mortality. Ecology 85:1332-1342

Foster BA (1971) Desiccation as a factor in the intertidal zonation of barnacles. Mar Biol 8:12-29

Freckleton RP (2002) On the misuse of residuals in ecology: regression of residuals vs. multiple regression. J Anim Ecol 71:542-545

Gaines S, Roughgarden J (1985) Larval settlement rate: a leading determinant of structure in an ecological community of the marine intertidal zone. Proc Natl Acad Sci USA 82:3707-3711

Hillebrand H (2004) On the generality of the latitudinal diversity gradient. Am Nat 163:192-211

Iwaki T (1975) Breeding and settlement of Chthamalus challengeri Hoek on the southern coast of Hokkaido. Bull Fish Hokkaido Univ 26:1-10

Johnson DW (2007) Habitat complexity modifies post-settlement mortality and recruitment dynamics of a marine fish. Ecology 88:1716-1725

Kado R (2003) Invasion of Japanese shores by the NE Pacific barnacle Balanus glandula and its ecological and biogeographical impact. Mar Ecol Prog Ser 249:199-206

Lewis JR (1964) The ecology of rocky shores. English Universities Press, London

Meadows PS, Campbell JI (1972) Habitat selection by aquatic invertebrates. Adv Mar Biol 10:271-382

- Menge B (2000) Recruitment vs. postrecruitment processes as determinants of barnacle population abundance. Ecol Monogr 70:265-288

Miyamoto Y, Noda T, Nakao S (1999) Zonation of two barnacle species not determined by competition. J Mar Biol Assoc UK 79:621-628

Morgan SG (2001) The larval ecology of marine communities. In: Bertness MD, Gaines SD, Hay ME (eds) Marine community ecology. Sinauer Associates, Sunderland, MA, p 159-181

Editorial responsibility: Richard Osman,

Edgewater, Maryland, USA
Nakaoka M, Ito N, Yamamoto T, Okuda T, Noda T (2006) Similarity of rocky intertidal assemblages along the Pacific Coast of Japan: effects of spatial scales and geographic distance. Ecol Res 21:425-435

> Noda T (2004a) Large-scale variability in recruitment of the barnacle Semibalanus cariosus: its cause and effects on the population density and predator. Mar Ecol Prog Ser 278:241-252

Noda T (2004b) Spatial hierarchical approach in community ecology: a way beyond high context-dependency and low predictability in local phenomena. Popul Ecol 46: $105-117$

> Okuda T, Noda T, Yamamoto T, Ito N, Nakaoka M (2004) Latitudinal gradient of species diversity: multi-scale variability in rocky intertidal sessile assemblages along the Northwestern Pacific coast. Popul Ecol 46:159-170

Pineda J, Riebensahm D, Medeiros-Bergen D (2002) Semibalanus balanoides in winter and spring: larval concentration, settlement and substrate occupancy. Mar Biol 140: $789-800$

> Power AM, Delany J, McGrath D, Myers AA, O'Riordan RM (2006) Patterns of adult abundance in Chthamalus stellatus (Poli) and C. montagui Southward (Crustacea: Cirripedia) emerge during late recruitment. J Exp Mar Biol Ecol 332:151-165

Quinn GP, Keough MJ (2002) Experimental design and data analysis for biologists. Cambridge University Press, Cambridge

Raimondi PT (1990) Patterns, mechanisms, consequences of variability in settlement and recruitment of an intertidal barnacle. Ecol Monogr 60:283-309

- Roughgarden J, Gaines S, Possingham H (1988) Recruitment dynamics in complex life cycles. Science 241:1460-1466

Schiel DR (2004) The structure and replenishment of rocky shore intertidal communities and biogeographic comparisons. J Exp Mar Biol Ecol 300:309-342

Sutherland JP (1987) Recruitment limitation in a tropical intertidal barnacle: Tetraclita panamensis (Pilsbry) on the Pacific coast of Costa Rica. J Exp Mar Biol Ecol 113: 267-282

> Svensson CJ, Jenkins SR, Hawkins SJ, Myers AA, Range P, Paula J, O'Riordan RM, Aberg P (2004) Models of open populations with space-limited recruitment in stochastic environments: relative importance of recruitment and survival in populations of Semibalanus balanoides. Mar Ecol Prog Ser 275:185-197

> Thorson G (1950) Reproductive and larval ecology of marine bottom invertebrates. Biol Rev Camb Philos Soc 25:1-45

Underwood AJ, Denley EJ (1984) Paradigms, explanations, and generalizations in models for the structure of intertidal communities on rocky shores. In: Strong D, Simberloff D, Abele LG, Thistle E (eds) Ecological communities: conceptual issues and the evidence. Princeton University Press, Princeton, NJ, p 151-180

> Walters LJ, Wethey DS (1996) Settlement and early post-settlement survival of sessile marine invertebrates on topographically complex surfaces: the importance of refuge dimensions and adult morphology. Mar Ecol Prog Ser 137: 161-171

Wethey DS (1986) Ranking of settlement cues by barnacle larvae: influence of surface contour. Bull Mar Sci 39:393-400

Submitted: June 27, 2009; Accepted: June 24, 2010

Proofs received from author(s): August 13, 2010 